OPEN ACCESS

Edited by:

Nuno Sousa,

University of Minho, Portugal

Reviewed by:

Carlos Tomaz,

University CEUMA, Brazil

John Roger Speakman,

Chinese Academy of Sciences

Beijing, China

${ }^{*}$ Correspondence:

Ralph J. DiLeone ralph.dileone@yale.edu

Received: 26 January 2016 Accepted: 13 June 2016 Published: 04 July 2016

Citation: Genné-Bacon EA, Trinko JR and DiLeone RJ (2016) Innate Fear-Induced Weight Regulation in the C57BL/6J Mouse.

Front. Behav. Neurosci. 10:132. doi: 10.3389/fnbeh.2016.00132

\section{Innate Fear-Induced Weight Regulation in the C57BL/6J Mouse}

\author{
Elizabeth A. Genné-Bacon ${ }^{1,2}$, Joseph R. Trinko ${ }^{1}$ and Ralph J. DiLeone ${ }^{1 *}$ \\ ${ }^{1}$ Division of Molecular Psychiatry, Ribicoff Research Facilities, Department of Psychiatry, Yale University School of Medicine, \\ New Haven, CT, USA, ${ }^{2}$ Department of Genetics, Yale University School of Medicine, New Haven, CT, USA
}

Regulation of body weight is an important strategy for small prey animals to avoid capture. Field and laboratory studies have shown that prey animals reduce body size when subjected to long-term predator stimuli. However, the causes of predatorinduced weight regulation are highly variable and the underlying mechanisms remain unclear. Understanding this phenomenon is important for gaining a better understanding of how animals regulate body weight under ethologically relevant conditions and has implications for obesity. Here we expose inbred C57BL/6J mice to a fearinducing odorant (2,4,5-trimethylthiazole; $\mathrm{mT})$ to model predation-induced weight regulation. Eight week-old mice were put on a $45 \%$ high fat diet (HFD) or chow diet (5\% fat) and exposed daily to $\mathrm{mT}$, an equally aversive dose of butyric acid (BA), or a neutral control scent (almond). mT-exposed mice in both diet groups gained significantly less weight over a 6-week period than BA-exposed mice. This differential weight gain appears unlikely to be due to differences in food intake and activity level, or brown adipose thermogenesis between the $\mathrm{mT}$ and BA groups. However, following chronic $\mathrm{mT}$ exposure we find increases in $\triangle$ FosB protein, a marker for long-term neural plasticity, in the dorsomedial hypothalamus (DMH)-an area previously implicated in chronic stress and defensive responses, as well as weight regulation. This study establishes a simplified and robust laboratory model of predation-mediated weight regulation with inbred lab mice and fear-inducing odor, and suggests a likely, yet undetermined, metabolic adaptation as contributing to this response.

Keywords: hypothalamus, weight regulation, mouse models, predator, obesity, $\Delta \mathrm{FosB}$, dorsomedial hypothalamic nucleus

\section{INTRODUCTION}

Proper body weight regulation is key to the survival of any animal. This is particularly true for small prey animals, which live under the continuous threat of predation. It is well-documented that prey animals, particularly birds and mammals, reduce body size when predators are present in their environment (Gosler et al., 1995; Lilliendahl, 1997; Carlsen et al., 1999; Gentle and Gosler, 2001; McNamara et al., 2005; Tidhar et al., 2007; Monarca et al., 2015b). This has been hypothesized to be an adaptive response, as smaller animals are able to move faster (Hedenstrom, 1992) and fit into a diverse array of hideaways (Sundell and Norrdahl, 2002), generally making them more difficult prey targets (Lima, 1986; Speakman, 2007). However, the mechanisms underlying this weight response are unclear. 
Both field and laboratory studies have produced mixed results on the behavioral and physiological mechanisms responsible for changes in weight after predator exposure. For example, field research (Sundell et al., 2004) has been inconsistent on the role of reduced foraging and food intake in contributing to weight loss (Lima and Bednekoff, 1999). This uncertainty may be due to the challenges of field methodology where many factors remain uncontrolled. Laboratory studies allow for better control of conditions, but have also yielded mixed results on the mechanisms underlying weight changes. For example, a laboratory study of predator scent exposure in field voles found a significant reduction of weight in predator-exposed animals compared to control animals, but no difference in food intake between groups (Carlsen et al., 1999). In contrast, Monarca's studies of predatory bird calls in wood mice (Monarca et al., 2015b) and C57BL/6J laboratory mice (Monarca et al., 2015a) found that weight differences were likely driven by alterations in food intake. Additionally, Tidhar's study of weasel feces exposure in bank voles found increased daily energy expenditure associated with reduced body weight, but variability in food intake differences (Tidhar et al., 2007). While these studies have advanced our understanding of predation-mediated weight regulation, there is still great need to standardize protocols to resolve discrepancies and better define the mechanisms involved.

Choice of predator stimulus is likely to influence the mechanisms underlying predator-mediated weight regulation. Scent is a particularly salient sense in rodents (Doty, 2012), and therefore most studies use the natural scent of predator feces, urine, or fur as a stimulus. While this strategy closely imitates conditions prey animals might encounter in the wild, it is difficult to fully control and replicate these natural scents between studies and subjects, making this approach somewhat limiting. Modeling predator stimulusmediated weight regulation with an easily controlled and replicable predator-like scent could help clarify mechanisms and compliment the work already done with other stimuli. 2,4,5trimethylthiazole $(\mathrm{mT})$ is a chemical structurally very similar to the red-fox derived predator scent 2,4,5-trimethylthiazoline (TMT; Brechbühl et al., 2013a; see "Materials and Methods" Section), and produces several innate fear responses such as avoidance (Brechbühl et al., 2013a) and freezing (Kobayakawa and Kobayakawa, 2011). Both TMT and mT are synthetic compounds, making them easily quantified and controlled, greatly reducing problems with variability encountered with natural predator stimuli.

Selection of animal model is also essential for reducing variation and standardizing protocols for studying predator responses. The C57BL/6J mouse is a commonly used laboratory mouse strain that offers an extensive genetic toolkit for more detailed neural studies of mechanisms that influence predator responses. Despite separation from wild conditions, it is known that $\mathrm{C} 57 \mathrm{BL} / 6 \mathrm{~J}$ mice do respond to a variety of predator stimuli (e.g., Cohen et al., 2008; Janitzky et al., 2015; Monarca et al., 2015a). Additionally, C57BL/6J mice gain weight on a high-fat diet, and are commonly used as a model for obesity and body weight regulation. Because of this, establishing the C57BL/6J mouse as a model for predatormediated weight regulation allows us to bridge knowledge gained from ecological studies with biomedical studies of weight regulation.

Defining mechanisms governing predator-mediated weight regulation are of both ecological and biomedical relevance. Understanding the neurobiological basis of predator responses will help to inform our view of predator-prey interactions in wild animals. Additionally, defining physiological and behavioral changes that regulate body weight under ethologically relevant conditions may improve our understanding of the etiology of obesity in these important model animals.

\section{MATERIALS AND METHODS}

\section{Animals}

All animals used were inbred male C57BL/6J and purchased from The Jackson Laboratory (Bar Harbor, ME, USA) between 7 and 8 weeks of age. Mice were group housed (five or three to a cage, except where indicated otherwise) in standard mouse cages, kept on a 12-h light/dark cycle (lights off at $7 \mathrm{pm}$ ), and provided ad libitum access to food and water. Mice were allowed to acclimate to our facility for at least 1 week prior to any manipulations and were between 8 and 10 weeks of age at the onset of experimentation. All experiments were carried out in accordance with Yale University Institutional Animal Care and Use Committee (IACUC) protocol.

\section{Scents and Controls}

\section{Note on TMT and $\mathrm{mT}$}

There are several distinct chemicals commonly referred to as "fox odor" in the literature, including: the cis- and transisomers of TMT (e.g., Vernet-Maury, 1980; Wallace and Rosen, 2000; Endres et al., 2005); 2,5-dihydro-2,4,5-trimethylthiazole, an isomer of the first chemicals, differing in placement of the ring double bond, (e.g., Vernet-Maury et al., 1984; Ihara et al., 2013); and $\mathrm{mT}$, an unsaturated variant of the first two chemicals (e.g., Mueller and Bale, 2008; Howerton and Bale, 2014). However, only the TMTs have been directly found in the secretions of the red fox, a natural predator of rodents (Vernet-Maury, 1980). Nonetheless, other researchers have sought to improve the predator fear-like response to fox odor by creating a variety of thiazole/ine-related fear odors, which produce similar or greater degrees of threat responses (Kobayakawa and Kobayakawa, 2011; Isosaka et al., 2015). $\mathrm{mT}$ was shown to produce similar levels of freezing compared to TMT (Kobayakawa and Kobayakawa, 2011). mT also activates the Grueneberg ganglion (Brechbühl et al., 2013a), an olfactory sub-system which is important for responses to alarm pheromones and predator scents, and required for TMT-induced freezing (Brechbühl et al., 2013b). Thus, though $\mathrm{mT}$ is itself not a predator odor, it is an innate fear-inducing odor, 
eliciting many of the behavioral and physiological responses of TMT.

The fear-inducing odor mT (Sigma Aldrich, 98\%) was used as a model of predator fear. Mice were exposed to all scents by pipetting liquid odorant onto a small square of KimWipe in a small $(4.6 \times 4.6 \mathrm{~cm})$ weigh boat and placing it in a standard mouse cage (or other apparatus where described) with the mice. Diluted concentrations of $\mathrm{mT}$ (see "Center Avoidance Test" Section below) were made by creating an emulsion with distilled water. Undiluted butyric acid ("BA", $\geq 99 \%$, Sigma-Aldrich, St. Louis, MO, USA), or almond scent (Badia Spices, Doral, FL, USA) were used for controls.

\section{Center Avoidance Test}

Four cages of group-housed mice (five per cage) were used to determine approximately equivalently aversive doses of $\mathrm{mT}$ and BA. Mice were first habituated to the testing apparatus for 2 days of 10-min sessions. The testing apparatus consisted of an open field box containing a smaller opaque box within the center of the field (the "center chamber" Figure 1A). Mice had access to the center chamber through a single opening. On the 3rd day water was presented in the center chamber for all cages. On the 4th day each cage of mice was presented with one of four possible scents/concentrations: $9.8 \mu \mathrm{lmT}$, 9.8 $\mu \mathrm{l} \mathrm{mT}$ diluted 1:1 in distilled water, 52.8 $\mu \mathrm{l} \mathrm{BA}$, and 105.6 $\mu \mathrm{l}$ BA. Time spent in the center chamber on $3 \mathrm{rd}$ and 4 th days was recorded and scored in real time using the behavioral software AnyMaze (Stoelting Co., Wood Dale, IL, USA).

\section{Chronic Scent Exposure Test}

To model predator-mediated weight regulation, we examined weight gain during daily $\mathrm{mT}$ scent exposure. Beginning on experiment day 0 , each cage of mice was taken to a separate room, put in a fresh standard cage with bedding, and presented with either $30 \mu \mathrm{l}$ almond scent, $52.8 \mu \mathrm{l} \mathrm{BA}$, or $9.8 \mu \mathrm{l} 50 \%$ $\mathrm{mT}$ for $30 \mathrm{~min}$. Scent exposures were repeated at approximately the same time each day (early afternoon-light period). After first scent exposure, high fat diet (HFD)-assigned animals were switched from chow (5\% Kcal from fat, RMH-3000, LabDiet, St. Louis, MO, USA) to a 45\% HFD (D12451, Research Diets, New Brunswick, NJ, USA). Mice were weighed every 3 days for 6 weeks. Weight data from chow-fed $\mathrm{mT}$ and BA groups were lost for experiment day 10 and so are not shown. Due to space limitations, the almond exposures were performed on a separate cohort from the $\mathrm{mT}$ and BA exposures. Conditions were kept the same between cohorts.

\section{Food Intake Measurements}

To measure food intake, the chronic scent exposure experiment (described above) of $\mathrm{mT}$ and $\mathrm{BA}$ was repeated using five cages per experimental group of paired-housed mice ( 20 mice total) fed a HFD. Body weight and food intake were recorded daily for a period of 6 weeks. Food intake was assessed by subtracting the amount of food remaining in the cages from the amount
A

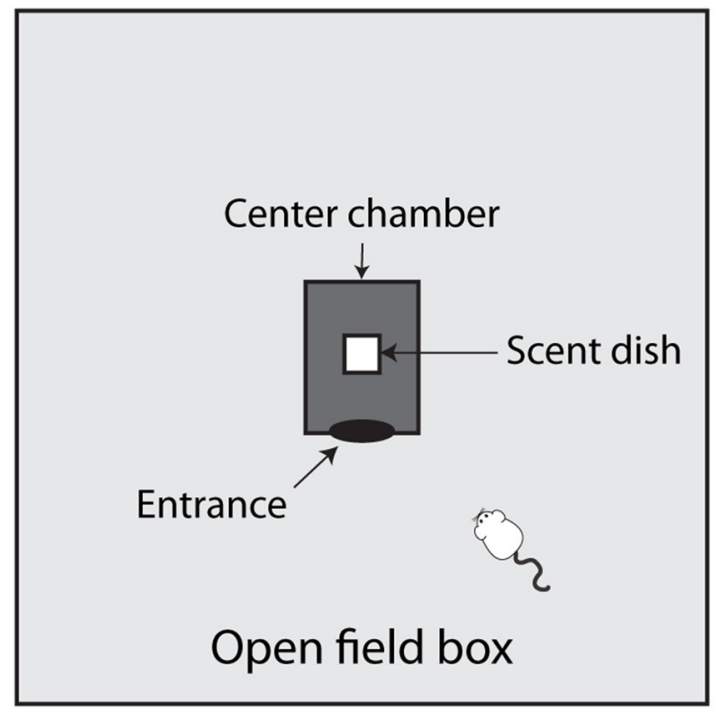

\section{B Percent of time in center chamber}

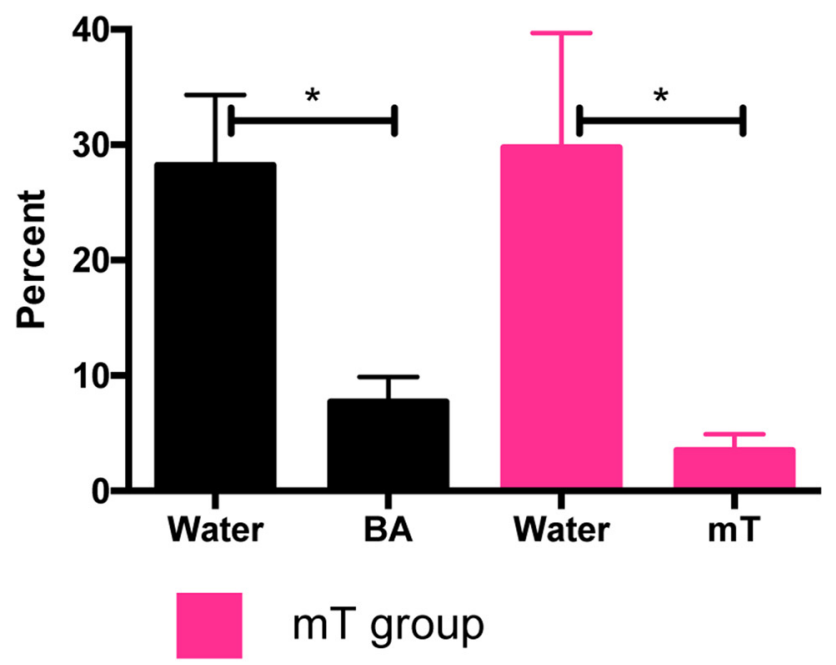

BA group

FIGURE 1 | Establishing an aversive control for 2,4,5-trimethylthiazole (mT). Four groups of mice ( $n=5$ per group) were habituated to an open field containing an opaque center chamber where either water or different quantities of $\mathrm{mT}$ and butyric acid (BA) were presented (A). Behavior was recorded over 10 min sessions and percent of time spent in the center chamber was compared between water and scent presentation. $52.8 \mu \mathrm{l}$ of BA and $9.8 \mu \mathrm{I}$ of $50 \% \mathrm{mT}$ produced approximately equal levels of avoidance (B). All error bars shown represent standard error of the mean (SEM). 
provided to the animals the previous day. Food spillage was minimal, and was assessed by visual inspection and accounted for when necessary.

\section{Locomotor Activity Measurements}

To measure locomotor activity, one mouse from each cage from the above food intake experiment cohort was removed from its home cage after 21 days of scent exposure and moved to individual cages containing food, water, and bedding, and placed in locomotor boxes (Med Associates, St Albans, VT, USA) at the onset of the night cycle. Locomotor activity counts were defined as consecutive beam breaks, and recorded using Med-PC IV software for a period of $22 \mathrm{~h}$.

To study locomotor activity in more detail, the chronic exposure protocol was again repeated, using group-housed mice (five mice per cage, one cage per scent group). To obtain a baseline reading prior to beginning of scent exposure and HFD, mice were placed in locomotor boxes (as described above) at approximately $3 \mathrm{pm}$ and removed $22 \mathrm{~h}$ later. Following the start of daily scent exposure, locomotor activity was reassessed weekly for a period of 4 weeks. On the days of locomotor activity testing, scent exposure was conducted during the 2 -h period prior to the beginning of locomotor testing. Locomotor boxes were located in a separate room.

\section{Corticosterone Measurements}

\section{Acute Exposure}

Group housed mice (five per cage) were habituated to the scent exposure setup for 2 days prior to sacrifice. On day of

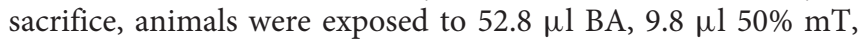
or $30 \mu \mathrm{l}$ almond scent for $30 \mathrm{~min}$, and then sacrificed by rapid decapitation and trunk blood was collected. Scent exposure and sacrifice was performed on separate days for different scent groups, at the same time each day (early afternoon). Two hundred fifty microliter of trunk blood was immediately added to $100 \mu \mathrm{l}$ of $2 \%$ EDTA (Sigma-Aldrich) and spun for $15 \mathrm{~min}$ at $2000 \mathrm{~g}$ at room temperature; plasma was collected as the supernatant.

\section{Chronic Exposure}

Animals from a separate cohort $(n=6$ per scent group, two cages of three mice each per group) of the chronic scent exposure experiment were sacrificed by rapid decapitation following the final scent exposure session (21 scent exposures total). Trunk blood was collected and processed as described above.

\section{Plasma CORT Measurements}

Plasma corticosterone (CORT) was measured with Assay Designs ELISA kits according to manufacturer's protocol, as described previously (Guarnieri et al., 2012). Briefly, $1 \mu \mathrm{l}$ of diluted plasma (1:50), was compared to known concentrations. An OD reading at $405 \mathrm{~nm}$ with correction at $570 \mathrm{~nm}$ was taken, a standard curve was generated, and unknowns were extrapolated using the Prism statistical software (GraphPad Software, La Jolla, CA, USA).

\section{Temperature Measurements}

To evaluate changes in body temperature, mice from the locomotor activity cohort (see above) were briefly anesthetized with isoflurane and implanted with IPTT-300 temperature transponders (Bio Medic Data Systems, Seaford, DE, USA). Temperatures were recorded with a non-invasive probe (DAS5007 IPTT pocket scanner, Bio Medic Data Systems) prior to daily scent exposure.

\section{Brown Adipose Tissue Dissection and qPCR}

To search for evidence of metabolic changes, uncoupling protein 1 (Ucp1) mRNA from brown adipose tissues (BAT) was measured in both chronic and acute scent-exposed mice. Chronic-exposure mice were sacrificed on the 36th day of scent exposure. Acute exposure tissue collection timing $(5 \mathrm{~h}$ post-scent) was based on peak Ucp1 mRNA expression timing from cold challenge studies (Nedergaard and Cannon, 2013). Following sacrifice by rapid decapitation, whole interscapular BAT was collected and quickly frozen on dry ice and stored at $-80^{\circ} \mathrm{C}$. RNA samples were purified from approximately $0.1 \mathrm{~g}$ of frozen BAT using Trizol reagent (Invitrogen, Carlsbad, CA, USA); a Nanodrop ND-100 (Thermo Fisher Scientific, Waltham, MA, USA) was used to quantify purified total RNA. cDNA samples were made from 1000 ng RNA using Superscript III Reverse Transcriptase kit and qPCR was carried out using Taqman gene expression kits. The $2^{-\Delta \Delta C t}$ method was used for calculating fold change compared to TATAbinding protein (Tbp) control (Livak, 2001). Primer kits used:

\section{- Mm01244861_m1 Ucp1 TaqMan ${ }^{\circledR}$ Gene Expression Assay (Thermo Fisher). \\ - Mm01277042_m1 Tbp TaqMan ${ }^{\circledR}$ Gene Expression Assay (Thermo Fisher).}

\section{Brain Dissection and $\Delta$ FosB Measurement}

To identify brain regions that may be involved in threat response, $\Delta$ FosB, a marker of neural plasticity, was measured after chronic scent exposure. Brains were collected after rapid decapitation and quickly frozen and stored at $-80^{\circ} \mathrm{C}$. Brains were then briefly partially thawed and then sectioned using a $1 \mathrm{~mm}$ brain block (BrainTree Scientific, Braintree, MA, USA) and each region was microdissected with guidance from the Mouse Brain Atlas (Paxinos and Franklin, 2004) using a scalpel, except for the nucleus accumbens (NAc) and Amygdala, where a 12 gauge circular punch was used. Protein extraction and analysis was carried out as described previously (Sears et al., 2010). Briefly, frozen tissue samples were sonicated and then boiled for $20 \mathrm{~min}$ in a $1 \%$ SDS lysis buffer solution containing 1:100 protease inhibitor (Sigma P8340) and 1:100 phosphatase inhibitors (Sigma P5726 and P0044). Total protein concentration was assessed with a Pierce bicinchoninic acid (BCA) protein assay (Thermo Fisher). One sample (BA\#1) from the medial hypothalamus (mHyp) had insufficient protein concentration and was excluded from further analysis. Equal quantities of protein $(55 \mu \mathrm{g})$ were separated by SDS polyacrylamide gel electrophoresis (Bio-Rad 
mini-PROTEAN TGX precast $12 \%$ polyacrylamide gels), and transferred to nitrocellulose membranes $(0.2 \mu \mathrm{m}$, Bio-Rad, Hercules, CA, USA). The membranes were immunoblotted using a 1:1000 dilution rabbit anti-FosB (Cell Signaling Technology, Danvers, MA, USA) and a 1:2000 dilution of mouse anti- $\beta$ actin (Cell Signaling). Antibody binding to FosB and $\triangle$ FosB was visualized by incubation with a 1:10,000 dilution of donkey antirabbit horseradish peroxidase-linked IgG (Vector Laboratories, Burlingame, CA, USA) and developed using Western Lightning Plus ECL chemiluminescence HRP substrate (PerkinElmer, Waltham, MA, USA) and a ChemiDoc imager (Bio-Rad). Antibody binding to $\beta$-actin was revealed using the LI-COR Odyssey quantitative infrared western blot detection system (IRDye 680LT secondary antibody, LI-COR, Lincoln, NE, USA). Band densities were analyzed using the Gel Analysis tool in ImageJ.

\section{FosB Immunofluorescence and Cell Counting}

Immunoflourescent labeling was used to visualize FosB $/ \Delta$ FosB protein expression in hypothalamic nuclei. Chow fed mice were exposed to 36 days of daily scent exposure (six mice per scent group) as described above. Ninety minutes following the final scent exposure animals were sacrificed through intracardial perfusion of $10 \%$ formalin, and brains were collected, processed, and cut to $40 \mu \mathrm{m}$ sections as described previously (Land et al., 2014). Staining for FosB (rabbit-antiFosB, Cell Signaling; 1:500) and secondary antibody (donkeyanti-rabbit Alexa 555; 1:500) was done in 3\% normal donkey serum and $0.3 \%$ Triton X-100. Tissue was visualized and images were captured using a fluorescent microscope, as described previously (Land et al., 2014). Images were taken at $10 \times$ magnification, with three $40 \mu \mathrm{m}$ sections quantified per animal. FosB labeling was quantified using ImageJ on matched sections by a researcher blinded to the experimental groups.

\section{Statistics and Analyses}

All statistical analyses were carried out using the Graph Pad Prism software package (version 6). Unpaired two-tailed $t$-tests were used for comparisons between two groups. Oneway ANOVA was used for comparison between more than two groups. Two-way repeated measures ANOVAs were used for comparisons of two or more groups over time. Tukey corrections for multiple comparisons were used to test for significance among individual groups within ANOVAs. Significance threshold (alpha) was set at 0.05 for most tests with levels of significance defined as follows: ${ }^{*} p \leq 0.05,{ }^{* *} p \leq 0.01$, ${ }^{* * *} p \leq 0.001$. For $\triangle$ FosB measurements in the brain, the Benjamini-Hochberg procedure (with a false discovery rate set at $Q=0.2$ ) was used to correct for multiple testing (adjusted alpha $=0.0286)$.

\section{RESULTS}

\section{Establishing an Aversive Control for mT}

Both $\mathrm{mT}$ and $\mathrm{TMT}$, in addition to being innate fear-inducing odors, are also aversive and noxious scents. BA is commonly used as a control for TMT due to its strong non-predator associated noxious odor (e.g., Morrow et al., 2000; Endres et al., 2005). In order to determine doses of $\mathrm{mT}$ and $\mathrm{BA}$ that were similarly aversive, we set up a test of avoidance of a center chamber inside an open field. Four separate groups of mice were exposed to different scent quantities (see Figure 1A), and time spent in the center chamber was scored and compared to a no-scent control session. We found $52.8 \mu \mathrm{l}$ of undiluted BA produced approximately equivalent levels of avoidance to $9.8 \mu \mathrm{l}$ of a $50 \%$ $\mathrm{mT}$ dilution (see Figure 1B). To examine the fear-inducing potential of these quantities of $\mathrm{BA}$ and $\mathrm{mT}$, we conducted a test for freezing (a common behavioral threat response; see Supplementary Methods). Although these quantities of BA and $\mathrm{mT}$ produce equal aversive behavior, we found $\mathrm{mT}$ significantly elevated freezing (a threat response) compared to BA, as well as to no-scent (water) and neutral scent controls $(p<0.0001)$. BA did not significantly elevate freezing compared to noscent or neutral scent control (see Supplementary Figure 1). These quantities were used in all subsequent scent exposure experiments.

\section{Chronic mT Exposure Attenuates Weight Gain in Both Low and High Fat Diets}

To determine if $\mathrm{mT}$ exposure will affect weight gain in C57BL/6 mice, six cages of group-housed mice ( $n=5$ per group) were exposed daily to $\mathrm{mT}, \mathrm{BA}$, or almond scent and given ad libitum access to either a $45 \%$ HFD or a standard chow ( $5 \%$ fat) diet. For the HFD-fed groups, there was a significant effect of scent ( $p=0.0024, F=10.43$; 2 -way ANOVA), day $(p<0.0001, F=366.8)$, and a significant interaction $(p<0.0001$, $F=15.27$ ). Animals exposed daily to $\mathrm{mT}$ gained significantly less weight over time than mice exposed to almond scent control $(p<0.05)$ or equally-aversive BA control $(p<0.01$; see Figures 2A,B). The BA-exposed group was not significantly different from the almond scent control in the HFD fed group. In the chow-fed group, differences were less robust. While a 2-way ANOVA revealed a significant main effect of scent $(p=0.0212$, $F=5.401$ ), as well as a significant interaction between scent and day ( $p<0.0001, F=4.290)$, testing for differences between individual scent groups revealed only significant differences between BA and $\mathrm{mT}$ groups $(p<0.05)$, while the almond group did not significantly differ from either (Figure $2 \mathrm{C}$ ). Total weight gained over the 6-week period was significantly lower in the $\mathrm{mT}$ exposed animals compared to BA-exposed animals in both diet groups (Figure 2D), with BA-exposed mice gaining an average of $3.32 \mathrm{~g}( \pm 1.023 \mathrm{~g})$ more than mT-exposed mice over the 6 week testing period for the HFD-fed group and $1.54 \mathrm{~g}( \pm 0.4512 \mathrm{~g})$ for the chow-fed group. As differences in weight gain between scent groups were more robust in HFD animals, we chose to focus primarily on this diet group for further experiments.

\section{mT Elevates Plasma Corticosterone After Acute and Repeated Exposures}

To determine approximate stress levels provoked by $\mathrm{mT}$ and $\mathrm{BA}$, we measured plasma CORT, a common marker of stress 


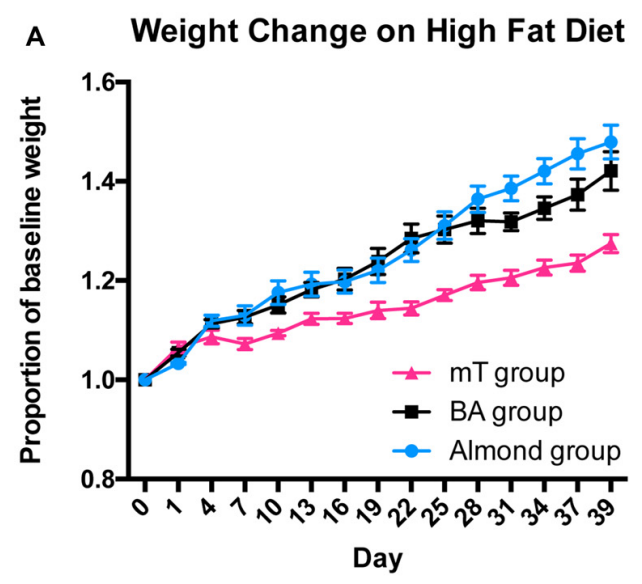

B

Total Weight Gained on High Fat Diet

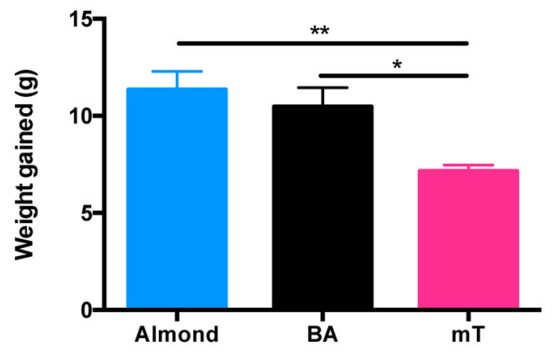

C Weight Change on Chow Diet

D
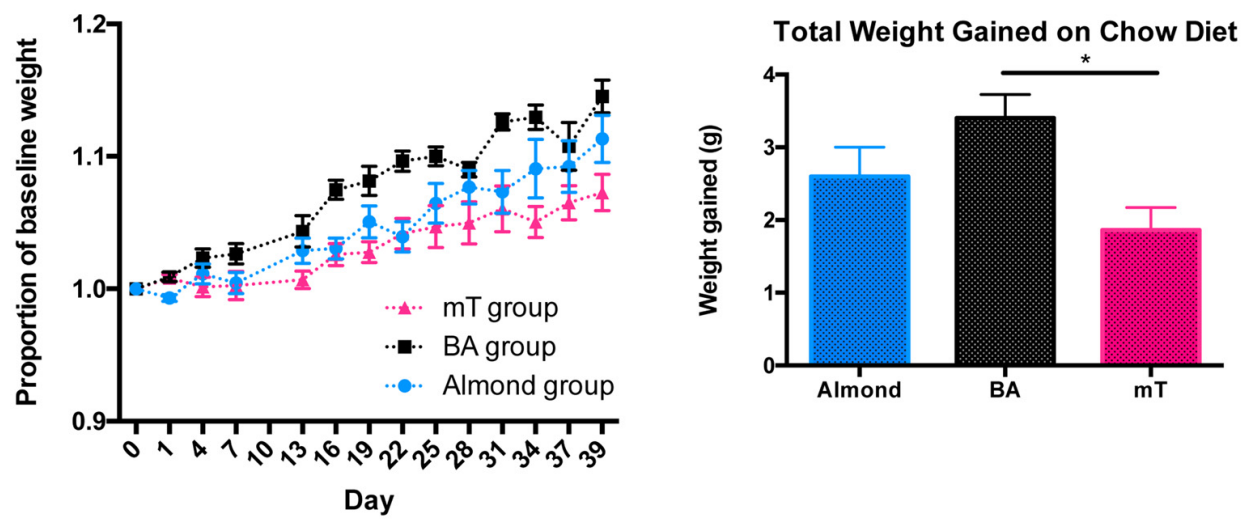

E

Plasma CORT levels Acute $\mathbf{3 0}$ minute scent exposure

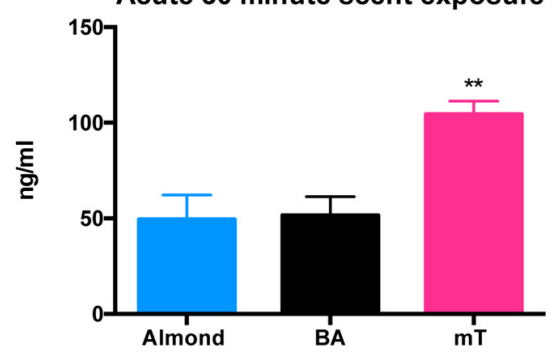

$\mathbf{F}$

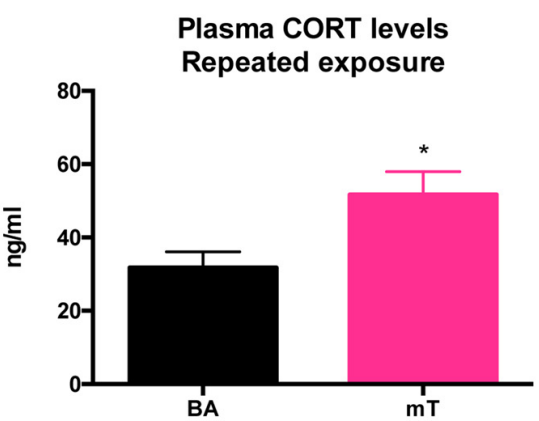

FIGURE 2 | Chronic $\mathbf{m T}$ exposure attenuates weight gain in both low and high fat diets (HFDs). Six cages of group housed ( $n=5$ per cage) were exposed daily to $9.8 \mu \mathrm{l} \mathrm{mT}, 52.8 \mu \mathrm{l} \mathrm{BA}$, or $30 \mu \mathrm{l}$ almond scent for 6 weeks while on a chow (5\% fat) or high fat (45\% fat, HFD) diet. (A) Weight gain on HFD presented as fold change from baseline weight. (B) Total weight gained on HFD at the end of the 6-week experiment. mT-exposed mice gained significantly less weight than BA or Almond exposed groups. (C) Weight gain on chow diet presented as fold change from baseline weight. (D) Total weight gained on chow diet. mT-exposed mice gained significantly less weight than BA-exposed mice on a chow diet. (E) Plasma corticosterone (CORT) levels from trunk blood after a single 30-min exposure to $9.8 \mu \mathrm{l} \mathrm{mT}, 52.8 \mu \mathrm{l} \mathrm{BA}$, or $30 \mu \mathrm{l}$ almond scent. (F) Plasma CORT levels from trunk blood after 3 weeks of daily scent exposure (and immediately after the final 30 min scent exposure). All error bars shown represent SEM.

in rodents, after acute (one time) and repeated scent exposure (21 days of daily exposure). Plasma CORT was significantly elevated ( $p=0.0026, F=10.74$; 1-way ANOVA) following a single exposure to $9.8 \mu \mathrm{l} 50 \% \mathrm{mT}$ compared to $52.8 \mu \mathrm{l} \mathrm{BA}$ or $30 \mu \mathrm{l}$ almond scent $(\mathrm{BA}=51.62 \mathrm{ng} / \mathrm{ml}$, Almond $=49.48 \mathrm{ng} / \mathrm{ml}$, $\mathrm{mT}=104.46 \mathrm{ng} / \mathrm{ml})$. Plasma CORT levels did not differ between
BA and almond scent exposures, suggesting differential stress responses despite equivalent aversion levels (See Figure 2E). Plasma CORT levels after repeated daily exposure to $\mathrm{mT}$ (Figure 2F) were also elevated compared to BA $(p=0.0248$, $\mathrm{BA}=24.08 \mathrm{ng} / \mathrm{ml}, \mathrm{mT}=39.45 \mathrm{ng} / \mathrm{ml}$ ), however plasma CORT levels following repeated $\mathrm{mT}$ exposure were significantly 


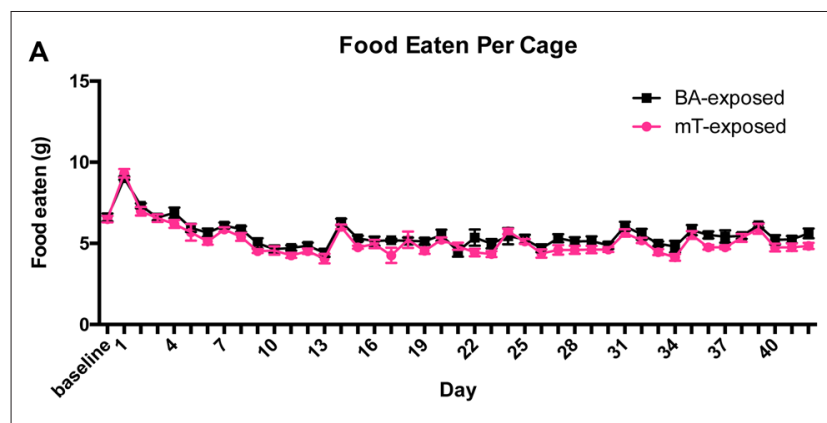

B

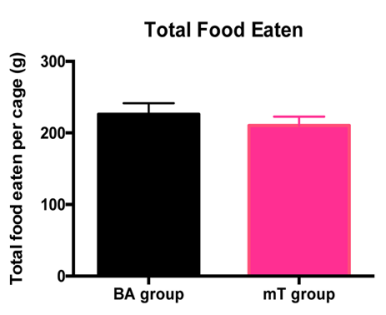

C

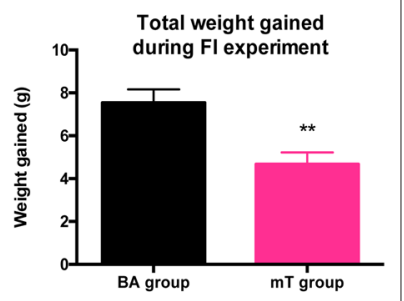

22-hour Locomotion Activity
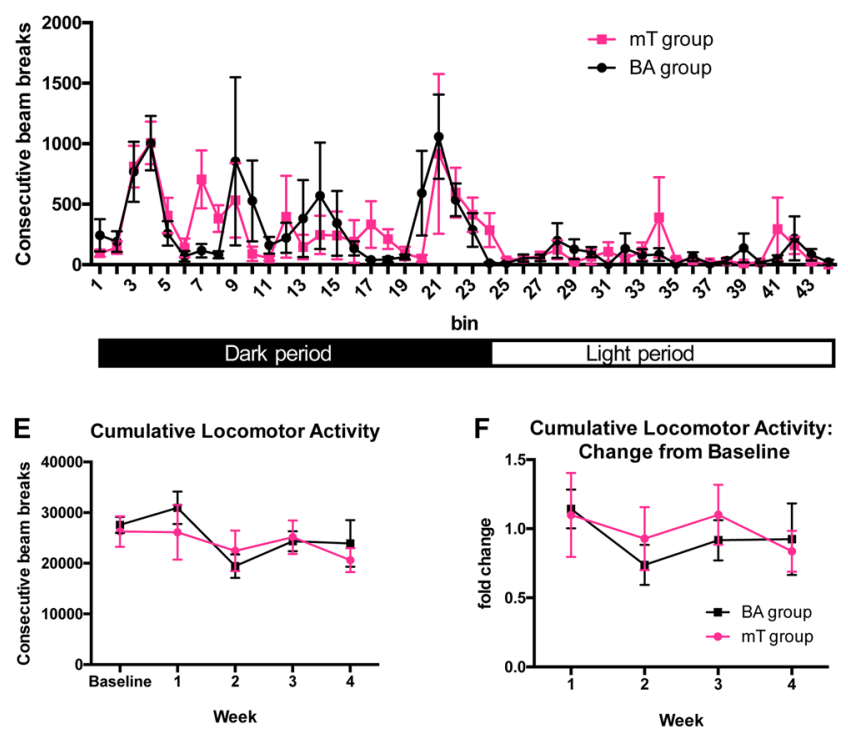

FIGURE 3 | Weight attenuation following chronic $m T$ exposure is not explained by differences in food intake or locomotor activity. (A) Daily food intake per cage (two mice per cage, five cages per group) of mice on HFD and experiencing daily scent exposure. (B) Total food intake per group over the 6-week experiment. (C) No differences were seen in food intake despite a significant attenuation of weight gain in $\mathrm{mT}$-exposed mice.

(D) Locomotor activity for mice undergoing daily scent exposure. Mice were placed in new locomotor boxes with bedding at the onset of the night cycle ( $\sim 5 \mathrm{~h}$ after daily scent exposure). Locomotor counts measured as two consecutive beam breaks. Black and white bar represents night/day cycle.

(E) Cumulative locomotor activity counts over 22-h periods for a new cohort of chronic scent-exposed mice tested for locomotor activity weekly.

(F) Cumulative locomotor counts divided by a pre-scent baseline day. All error bars shown represent SEM.

decreased ( $p=0.0007$, mean difference of $35.16 \pm 7.01 \mathrm{ng} / \mathrm{ml}$ comparing Figures 2E,F) compared to after only a single exposure.

\section{Chronic mT does not Significantly Change Food Intake}

To determine if the difference in weight gain between $\mathrm{mT}$ and BA-exposed mice could be driven by differences in food intake, an independent cohort of animals housed two to a cage $(n=5$ cages per experimental group and $n=10$ animals per group total) was put on $45 \%$ HFD and exposed daily to $\mathrm{mT}$ or BA for a period of 6 weeks with food intake and body weight measured daily. As expected, $\mathrm{mT}$-exposed animals gained significantly less weight than BA-exposed animals when put on HFD (2-tailed $t$-test: $p=0.0028$, Figure 3C). However, there was no significant difference between groups for food intake over time (scent: $p=0.1179, F=3.068$; 2-way ANOVA, see Figure 3A) or total food eaten between groups ( $p=0.1148$, 2-tailed $t$ test; see Figure 3B).

\section{Chronic mT Exposure does not Affect Locomotor Activity}

To determine if changes in physical activity could be driving differences in weight gain, this cohort of animals was also tested for locomotor activity over a 22-h period. Following daily scent exposure, one mouse from each of the double-housed cages was placed in a locomotor box and activity was recorded over a 22-h period. No differences in the pattern of locomotion (as measured by consecutive beam breaks) were detected between groups (Figure 3D). To further assess potential differences in physical activity, an independent cohort was subjected to the chronic scent exposure test. Locomotor activity in these mice was recorded for 22 -h periods once per week, including a baseline reading prior to any scent exposure. Again, no differences in the hourly circadian rhythm of locomotor activity was observed between groups, nor were changes observed over time (Figures 3E,F), despite a significant difference in weight gain between groups (BA: $6.86 \mathrm{~g}$ gained, $\mathrm{mT}$ : $3.6 \mathrm{~g}$ gained; $p=0.0008,2$-tailed $t$-test, see Supplementary Figure 2).

\section{Chronic mT does not Change Body Temperature or Uncoupling Protein mRNA Levels}

To investigate a potential thermogenic effect of stress contributing to differences in weight gain, we recorded daily temperatures in chronic $\mathrm{mT}$ exposed animals. Transponders were inserted subdermally between the scapulae and no main effect of $\mathrm{mT}$ on temperature was detected $(p=0.4495$, $F=0.6322$; Figure $4 \mathrm{~A}$ ). We also tested a molecular marker of thermogenesis: UCP1 mRNA from BAT using qPCR. A new chronic scent exposure cohort (with both HFD and chowfed groups, $n=6$ per treatment/food group) was sacrificed and BAT collected from each animal after 36 days of scent exposure. No differences in Ucp1 mRNA level were detected between scent groups in either HFD (Figure 4B) or chow (Figure 4C) fed groups. We additionally measured Ucp1 mRNA from BAT following an acute (one-time) scent exposure in naive animals, but again did not see any changes in Ucp1 mRNA expression between scent groups (See Supplementary Figure 3). 


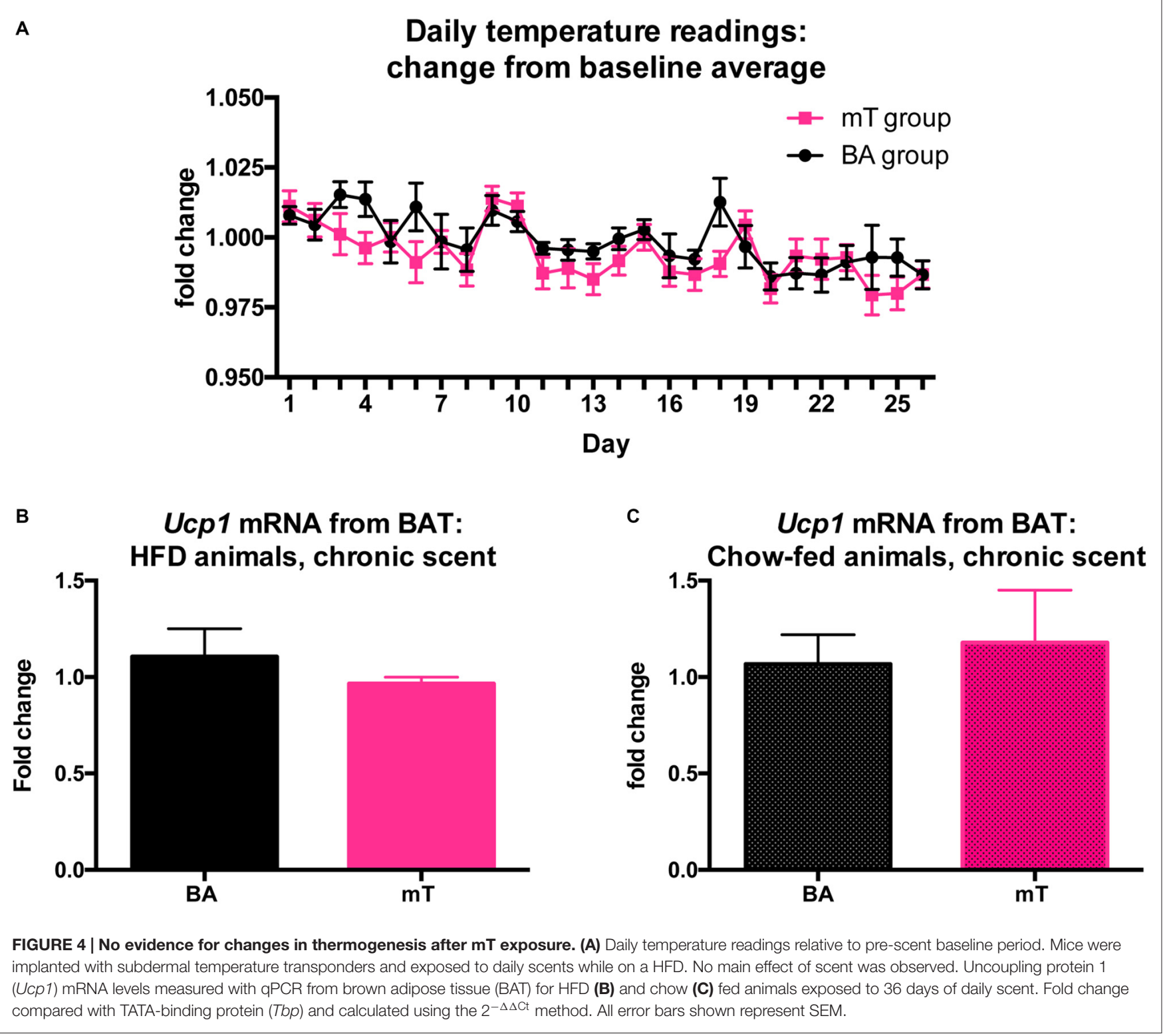

\section{Changes in a Marker of Neural Plasticity Following Repeated mT Exposure}

To investigate which regions of the brain may be involved in the response to chronic $\mathrm{mT}$ exposure, we measured $\Delta \mathrm{FosB}$, a marker of long-term neural plasticity, in a survey of several brain regions previously implicated in TMT and other predator threat responses. Following 6 weeks of $\mathrm{mT}$ or BA scent exposure ( $n=5$ per scent group), chow-fed mice were sacrificed and brains sectioned in a brain block to $1 \mathrm{~mm}$ slices. Brain tissue from the septal nucleus (LS), NAc (core and shell), bed nucleus of the stria terminalis (BNST), anterior hypothalamus (AHN), mHyp (encompassing both the dorsomedial and ventromedial hypothalamic nuclei), amygdala (basolateral), and whole hippocampus was dissected (Supplementary Figure 4), isolated, and FosB and $\triangle$ FosB protein levels measured with western blot. We found significant elevation of $\triangle \mathrm{FosB}$ protein between $\mathrm{mT}$ and BA exposed mice in the $\mathrm{mHyp}(p=0.024$, 2 -tailed $t$ test), despite no change in total $\operatorname{FosB}(p=0.256)$ or $\beta$-actin ( $p=0.692$; Figure 5). No differences in FosB or $\Delta$ FosB protein levels were detected in any other brain region.

To visualize which fine structure(s) in the mHyp may be contributing to differential $\triangle \mathrm{FosB}$ protein expression, immunofluorescent staining of total FosB $/ \Delta$ FosB protein in the mHyp was carried out on perfused brain tissue from chronically scent exposed, chow fed mice. We found a significantly higher number of FosB $/ \Delta$ FosB positive cells in the dorsomedial hypothalamus $(\mathrm{DMH})$ in $\mathrm{mT}$-exposed mice (2-tailed $t$-test, $p=0.0047$, see Figure 6). Very little, if any, FosB $/ \Delta$ FosB expression was observed in the ventromedial hypothalamus (VMH) in either scent group. 
A

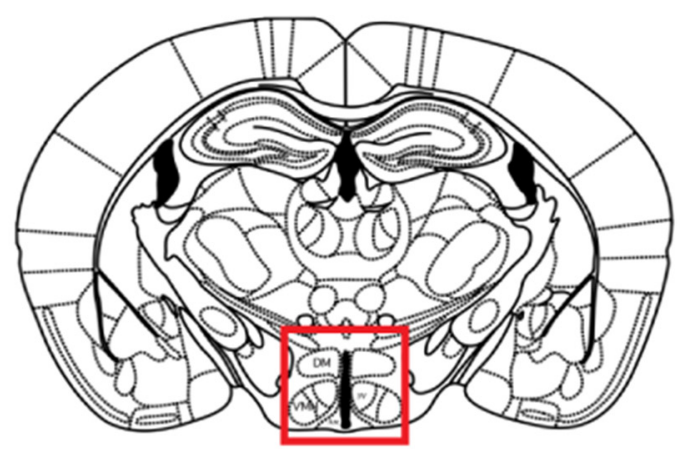

B

Ladder
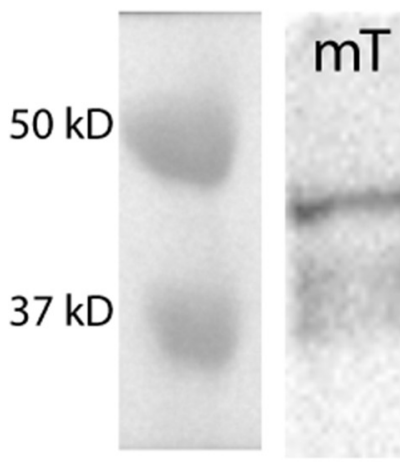

BA

c Ladder
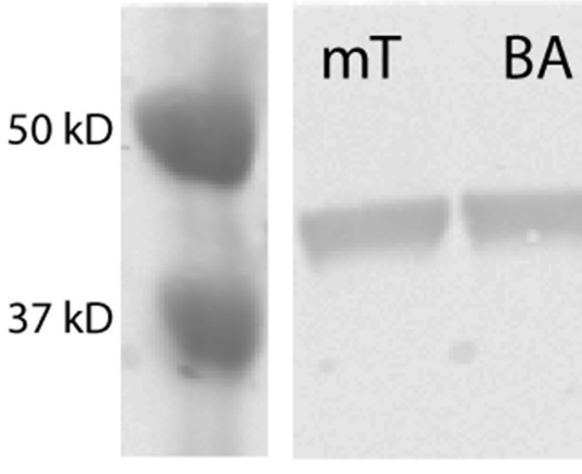

FIGURE 5 | $\Delta$ FosB levels are increased in the medial hypothalamus (mHyp) following repeated $\mathbf{m T}$ exposure. Western blots for FosB and $\beta$-actin (loading control) were carried out on fresh-frozen brain tissue dissected from the $\mathrm{mHyp}$ (A). Protein bands were distinguished by size (B,C). Band intensities were calculated using ImageJ gel analysis tools. $\triangle$ FosB protein levels were significantly elevated (D) in the mHyp following 6 weeks of daily mT exposure compared to BA-exposed mice. Neither FosB levels (E), nor $\beta$-actin (F) differed between scent groups. All error bars shown represent SEM.

\section{DISCUSSION}

In this study we find significant attenuation of weight gain in C57BL/6J mice on both a high fat and low fat diet when exposed daily to a threatening scent compared to a non-
FosB

\section{$\triangle \mathrm{FosB}$}

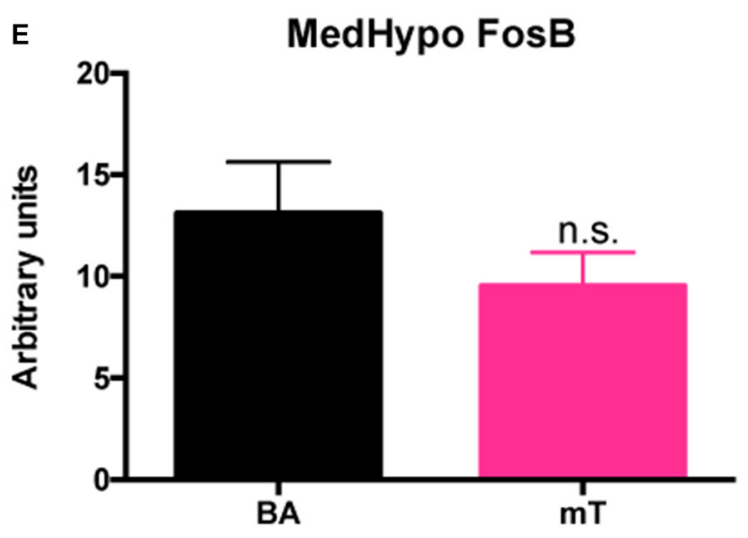

$\mathbf{F}$

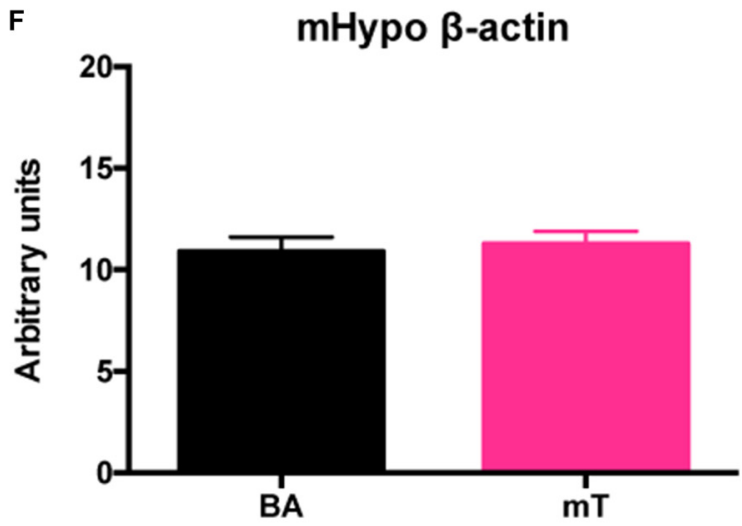

$\beta$-actin

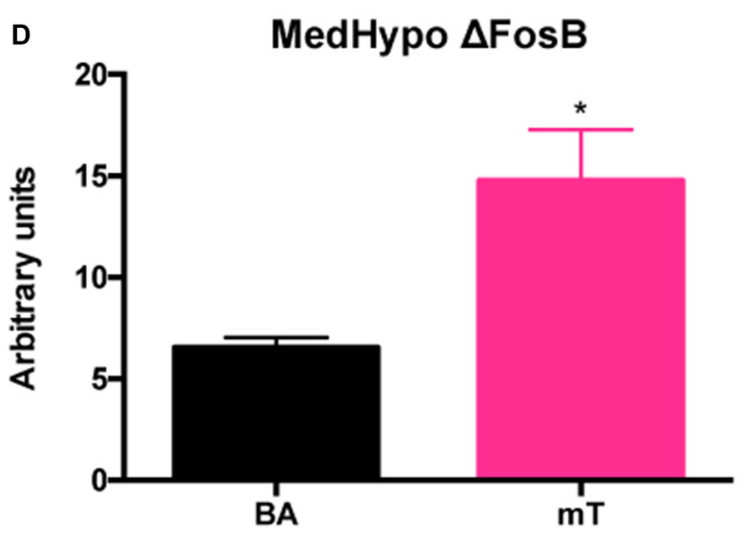




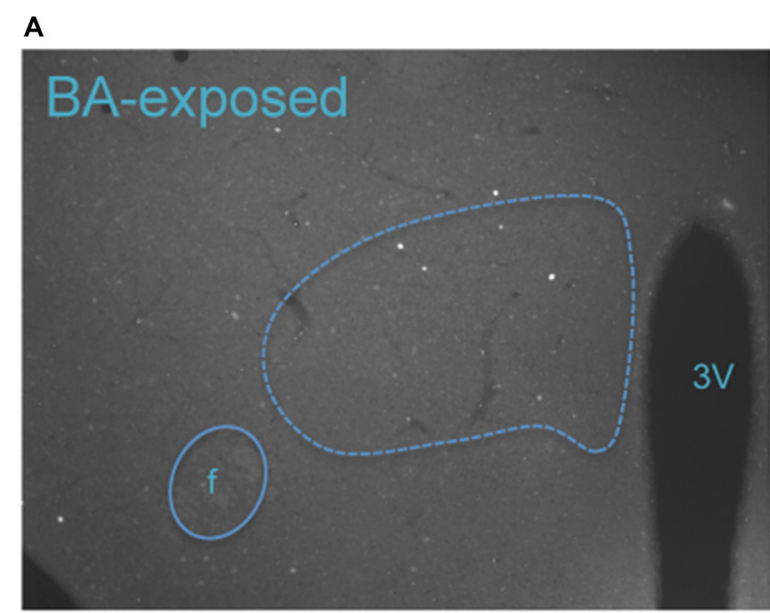

B

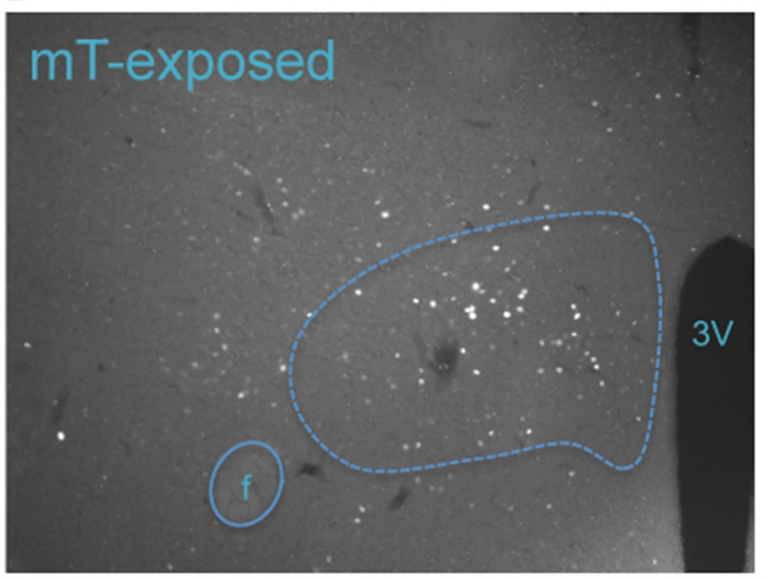

C

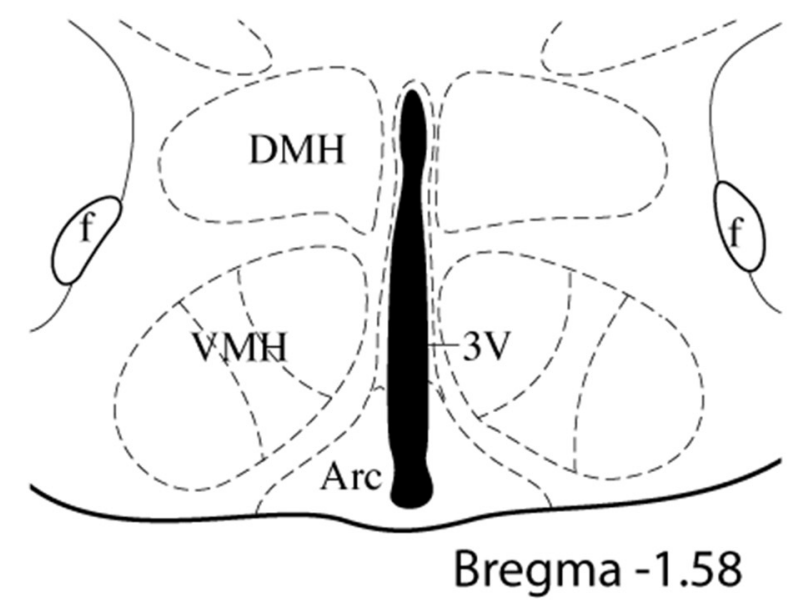

D

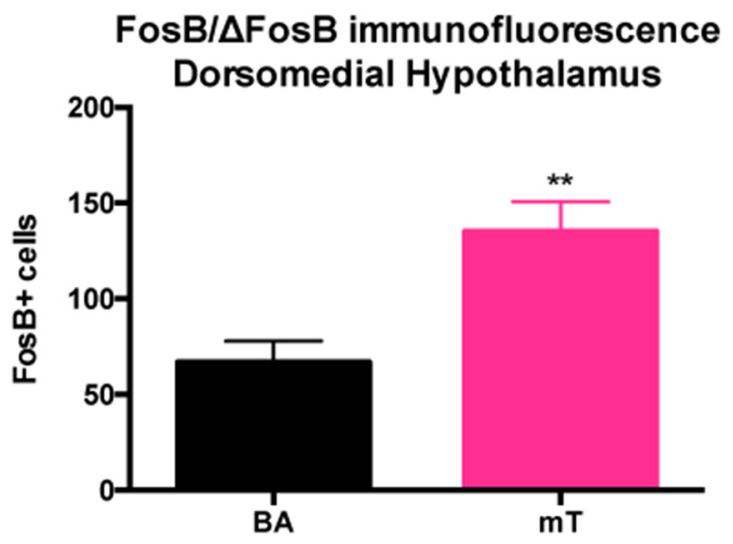

FIGURE 6 | FosB/AFosB levels are increased specifically in the dorsomedial hypothalamus (DMH) following repeated $m T$ exposure. FosB/ $\triangle$ FosB immunofluorescent staining was carried out on perfused brain tissue from chronic scent-exposed mice. (A,B) Representative images of FosB/ $\Delta$ FosB expression in the $\mathrm{DMH}$ in a BA or mT-exposed mouse brain, respectively. Dotted line represents DMH based on approximate brain region boundaries (C) from Paxinos and Franklin (2004); 3V, third ventricle, f, fornix, VMH, ventromedial hypothalamus, Arc, arcuate nucleus. Significantly more FosB/ $\Delta$ FosB positive cells were counted in the DMH of chronically mT-exposed mice, compared to BA-exposed (D). Error bars shown represent SEM.

to be involved in processing predator threat (Canteras, 2002). This study provides additional evidence for the role of predation stimuli in regulation of body weight in rodents, and demonstrates that predation-mediated weight reduction can be modeled using inbred laboratory mice and a synthetic fear-inducing olfactory stimulus.

We find that $\mathrm{mT}$-exposure attenuates weight gain in mice on both high and low fat diets, with HFD showing more robust and consistent changes. This is likely due to the relatively small overall weight gain seen in each scent group for the chow fed animals. HFD provokes a larger change in weight, making the differences between scent groups more distinct. Additionally this study uses only relatively young, male mice, and different responses may be seen in different age groups or sexes.

Previous studies have implicated alterations in food intake and physical activity to explain predator-mediated weight regulation (Tidhar et al., 2007; Monarca et al., 2015a,b). However, we find no evidence to support the contribution of these behaviors to the difference in weight with $\mathrm{mT}$ exposure. It is possible for the differences we see in weight gain to be due to very small changes in food intake that we lack the power to detect. However, our results are in contrast to a similar study with auditory cues, where changes in weight of C57BL/6J mice were clearly driven by differences in food intake (Monarca et al., 2015a). This conflict is not without precedent, as other studies have found no difference or mixed differences in food intake or foraging behavior with exposure to predator stimuli (Carlsen et al., 1999; Sundell et al., 2004). It is likely that these discrepancies are due to differences between experimental protocol, species used, or chosen stimulus. For example, diurnal timing of scent exposure may affect factors such as food intake, and presenting scent during the animals' 
natural feeding period could result in greater changes in food intake than observed here. Further studies controlling for each of these variables of predator stimulus presentation will help to tease apart the complex factors that encompass predator threat response.

This study uses $\mathrm{mT}$, a fear-inducing odor structurally very similar to the predator odor TMT, which is found in the excretions of red fox anal glands (Vernet-Maury, 1980; Brechbühl et al., 2013a). We are able to recapitulate several previously observed components of predator-mediated weight regulation (e.g., reduced body weight, increases in $\Delta$ FosB in the mHyp), while others (e.g., food intake changes) are absent. It is possible that $\mathrm{mT}$ is not a close enough mimic of predator stimuli, and further studies should be done to directly compare $\mathrm{mT}$ with TMT and with other predator odors. There is also evidence that single-molecule odorants, such as TMT, do not elicit the full range of predator threat responses in rodents (Staples et al., 2008; Pagani and Rosen, 2009). It is possible that we are observing a very specific component of the complete predator scent response repertoire and other responses require different stimuli. Several other single-molecule predator-associated odorants have now been discovered (Rosen et al., 2015), and these may elicit other predator-threat responses seen in response to natural predator odors but not to TMT or mT.

The underlying mechanism for the mT-provoked weight response seen in our animals remains unclear. Because there were no detectable changes observed in food intake or physical activity, metabolic changes are suspected. Metabolic changes have been previously implicated in weight response to chronic stress (Michel et al., 2005; Harris, 2015), as well as specifically to predator-mediated weight regulation (Tidhar et al., 2007). We find equally aversive fear-inducing odor and non-fear inducing control odors elicit different CORT responses, with $\mathrm{mT}$-exposed mice showing elevated CORT levels both acutely and chronically, indicating that our mTexposed animals are under chronic stress (Tidhar et al., 2007).

Stress-induced hyperthermia has been proposed as the primary metabolic component of stress-induced weight loss (Arase et al., 1988). BAT is the body's primary source of non-shivering thermogenesis and known to be activated by certain kinds of stress (Ricquier and Mory, 1984; Cannon and Nedergaard, 2004). Because of this, we measured expression of the primary heat-producing molecule of BAT, UCP1, from intrascapular BAT through qPCR of Ucp1 mRNA in chronically $\mathrm{mT}$-exposed mice. We found no differences in BAT Ucp 1 mRNA expression between scent groups after repeated $\mathrm{mT}$ exposure. Though mRNA expression is only a proxy-measurement for the thermogenic capacity of BAT (Nedergaard and Cannon, 2013), we also did not see corresponding changes in body temperature from intrascapularly placed temperature transponders, leading us to conclude that local thermogenesis is likely not a major contributor to $\mathrm{mT}$-induced weight attenuation.

This study finds increases in expression of $\Delta$ FosB protein, a persistent transcription factor involved in long-term regulation of gene expression, in the mHyp following 6 weeks of daily exposure to a fear-inducing, predator-like stimulus. This is consistent with increases in $F o s B / \triangle F o s B$ mRNA seen in the mHyp of Bradt's voles after repeated exposure to cat feces, as well as changes in FosB $/ \Delta$ FosB immunoreactivity in the $\mathrm{VMH}$ (dorsomedial region-VMHdm) of rats after repeated exposure to cat fur (Staples et al., 2009; Hegab et al., 2014). To our knowledge, our study is the first to confirm it is $\triangle$ FosB protein, a truncated isoform of FosB known to mediate long-term neural plasticity, that is elevated in this region, as no differences were detected for FosB protein between scent groups. Additionally, the comparatively long time course used for our study indicates that this region is highly resistant to habituation and/or continues to be important to long-term threat responses.

Interestingly, previous evidence for the mHyp's role specifically in TMT-response (as opposed to other predator odors) has been mostly negative. While the role of the VMHdm in response to natural predator odors such as cat fur is well established (Canteras, 2002), multiple studies show no immediate early gene activation in the VMHdm following TMT exposure (Staples et al., 2008; Pérez-Gómez et al., 2015). Similarly, we observed low expression of FosB $/ \Delta$ FosB in the $\mathrm{VMH}$ (including the VMHdm) of chronically mT-exposed mice, but do see a robust increase in FosB/ $\Delta$ FosB in the $\mathrm{DMH}$ in $\mathrm{mT}$-exposed mice. Since protein expression from our western blot shows no differences in FosB in the mHyp, the increased number of FosB+ immunofluorescent cells in the $\mathrm{DMH}$ is likely driven by increases in $\triangle \mathrm{FosB}$. The $\mathrm{DMH}$ is a region known to be involved in stress response and body weight regulation (DiMicco et al., 2002; DiMicco and Zaretsky, 2007), and increases in FosB/ $\Delta$ FosB protein expression have been previously observed in the DMH following repeated restraint stress (Flak et al., 2012). More specifically, the DMH mediates the metabolic, but not the anorectic, responses to leptin (Rezai-Zadeh et al., 2014). This is consistent with our finding that chronic $\mathrm{mT}$ exposure does not attenuate weight gain through changes in food intake, and suggests that changes in DMH neural activity may influence body weight via a metabolic mechanism.

In summary, the current data add to the complex picture of predator threat response and weight regulation in prey mammals. We demonstrate that C57BL/6J laboratory mice will regulate their body weight in response to fear-inducing odor, but that this response, at least for $\mathrm{mT}$, is likely not mediated through changes in food intake. Interestingly, we find that this weight regulation occurs regardless of dietary fat content, demonstrating the broad influence of innate threat in regulation of body weight even in the context of obesogenic diet. More study of this ecologically relevant and obesity-preventing neurophysiological pathway is important for gaining a broader picture of the biology of weight regulation.

\section{AUTHOR CONTRIBUTIONS}

EAG-B conceived, designed, and conducted experiments, analyzed data, interpreted results, and wrote the manuscript. JRT conducted experiments and edited manuscript. RJD helped 
conceive and design experiments, interpreted results, and revised manuscript. All authors approved the submitted version.

\section{FUNDING}

National Science Foundation Graduate Research Fellowship to EAG-B.

\section{ACKNOWLEDGMENTS}

We thank members of the DiLeone lab for help and technical advice. We also thank Carol Gianessi for laboratory help

\section{REFERENCES}

Arase, K., York, D. A., Shimizu, H., Shargill, N., and Bray, G. A. (1988). Effects of corticotropin-releasing factor on food intake and brown adipose tissue thermogenesis in rats. Am. J. Physiol. 255, E255E259.

Brechbühl, J., Moine, F., and Broillet, M.-C. (2013a). Mouse Grueneberg ganglion neurons share molecular and functional features with C. elegans amphid neurons. Front. Behav. Neurosci. 7:193. doi: 10.3389/fnbeh.2013. 00193

Brechbühl, J., Moine, F., Klaey, M., Nenniger-Tosato, M., Hurni, N., Sporkert, F., et al. (2013b). Mouse alarm pheromone shares structural similarity with predator scents. Proc. Natl. Acad. Sci. U S A 110, 4762-4767. doi: 10.1073/pnas. 1214249110

Cannon, B., and Nedergaard, J. (2004). Brown adipose tissue: function and physiological significance. Physiol. Rev. 84, 277-359. doi: 10.1152/physrev. 00015.2003

Canteras, N. S. (2002). The medial hypothalamic defensive system: hodological organization and functional implications. Pharmacol. Biochem. Behav. 71, 481-491. doi: 10.1016/s0091-3057(01)00685-2

Carlsen, M., Lodal, J., Leirs, H., and Secher Jensen, T. (1999). The effect of predationrisk on body weight in the field vole, Microtus agrestis. Oikos 87, 277-285. doi: 10.2307/3546742

Cohen, H., Geva, A. B., Matar, M. A., Zohar, J., and Kaplan, Z. (2008). Posttraumatic stress behavioural responses in inbred mouse strains: can genetic predisposition explain phenotypic vulnerability? Int. J. Neuropsychopharmacol. 11, 331-349. doi: 10.1017/s1461145707007912

DiMicco, J. A., Samuels, B. C., Zaretskaia, M. V., and Zaretsky, D. V. (2002). The dorsomedial hypothalamus and the response to stress: part renaissance, part revolution. Pharmacol. Biochem. Behav. 71, 469-480. doi: 10.1016/s00913057(01)00689-x

DiMicco, J. A., and Zaretsky, D. V. (2007). The dorsomedial hypothalamus: a new player in thermoregulation. Am. J. Physiol. Regul. Integr. Comp. Physiol. 292, R47-R63. doi: 10.1152/ajpregu.00498.2006

Doty, R. (2012). Mammalian Olfaction, Reproductive Processes, and Behavior. Amsterdam: Elsevier.

Endres, T., Apfelbach, R., and Fendt, M. (2005). Behavioral changes induced in rats by exposure to trimethylthiazoline, a component of fox odor. Behav. Neurosci. 119, 1004-1010. doi: 10.1037/0735-7044.119.4.1004

Flak, J. N., Solomon, M. B., Jankord, R., Krause, E. G., and Herman, J. P. (2012). Identification of chronic stress-activated regions reveals a potential recruited circuit in rat brain. Eur. J. Neurosci. 36, 2547-2555. doi: 10.1111/j.1460-9568. 2012.08161.x

Gentle, L. K., and Gosler, A. G. (2001). Fat reserves and perceived predation risk in the great tit, Parus major. Proc. Biol. Sci. 268, 487-491. doi: 10.1098/rspb.2000. 1405

Gosler, A. G., Greenwood, J., and Perrins, C. (1995). Predation risk and the cost of being fat. Nature 377, 621-623. doi: 10.1038/377621a0

Guarnieri, D. J., Brayton, C. E., Richards, S. M., Maldonado-Aviles, J., Trinko, J. R., Nelson, J., et al. (2012). Gene profiling reveals a role for stress hormones in the molecular and behavioral response to food restriction. Biol. Psychiatry 71, 358-365. doi: 10.1016/j.biopsych.2011.06.028 when needed and Dr. Jane Taylor for advice and use of testing boxes. We also thank Dr. Elena Gracheva for use of temperature transponders, Dr. Elise Jeffery for demonstrating BAT dissections, and Dr. Louise Guard for her help with understanding predator odor chemical structures.

\section{SUPPLEMENTARY MATERIAL}

The Supplementary Material for this article can be found online at: http://journal.frontiersin.org/article/10.3389/fnbeh.2016.00 132 /abstract

Harris, R. B. S. (2015). Chronic and acute effects of stress on energy balance: are there appropriate animal models? Am. J. Physiol. Regul. Integr. Comp. Physiol. 308, R250-R265. doi: 10.1152/ajpregu.00361.2014

Hedenstrom, A. (1992). Flight performance in relation to fuel load in birds. J. Theor. Biol. 158, 535-537. doi: 10.1016/s0022-5193(05)80714-3

Hegab, I. M., Shang, G., Ye, M., Jin, Y., Wang, A., Yin, B., et al. (2014). Defensive responses of Brandt's voles (Lasiopodomys brandtii) to chronic predatory stress. Physiol. Behav. 126, 1-7. doi: 10.1016/j.physbeh.2013.12.001

Howerton, C. L., and Bale, T. L. (2014). Targeted placental deletion of OGT recapitulates the prenatal stress phenotype including hypothalamic mitochondrial dysfunction. Proc. Natl. Acad. Sci. US A 111, 9639-9644. doi: 10. 1073/pnas.1401203111

Ihara, S., Yoshikawa, K., and Touhara, K. (2013). Chemosensory signals and their receptors in the olfactory neural system. Neuroscience 254, 45-60. doi: 10. 1016/j.neuroscience.2013.08.063

Isosaka, T., Matsuo, T., Yamaguchi, T., Funabiki, K., Nakanishi, S., Kobayakawa, R., et al. (2015). Htr2a-Expressing Cells in the Central Amygdala Control the Hierarchy between Innate and Learned Fear. Cell 163, 1153-1164. doi: 10.1016/j.cell.2015.10.047

Janitzky, K., D’Hanis, W., Kröber, A., and Schwegler, H. (2015). TMT predator odor activated neural circuit in C57BL/6J mice indicates TMT-stress as a suitable model for uncontrollable intense stress. Brain Res. 1599, 1-8. doi: 10. 1016/j.brainres.2014.12.030

Kobayakawa, K., and Kobayakawa, R. (2011). Animal repellents. US Patent WO 2011096575A1.

Land, B. B., Narayanan, N. S., Liu, R.-J., Gianessi, C. A., Brayton, C. E., Grimaldi, D. M., et al. (2014). Medial prefrontal D1 dopamine neurons control food intake. Nat. Neurosci. 17, 248-253. doi: 10.1038/nn.3625

Lilliendahl, K. (1997). The effect of predator presence on body mass in captive greenfinches. Anim. Behav. 53, 75-81. doi: 10.1006/anbe. 1996.0279

Lima, S. L. (1986). Predation risk and unpredictable feeding conditions: determinants of body-mass in birds. Ecology 67, 377-385. doi: 10.2307/1938580

Lima, S. L., and Bednekoff, P. A. (1999). Temporal variation in danger drives antipredator behavior: the predation risk allocation hypothesis. Am. Nat. 153, 649-659. doi: 10.1086/303202

Livak, K. (2001). Analysis of relative gene expression data using real-time quantitative PCR and the $2^{-\Delta \Delta C T}$ method. Methods 25, 402-408. doi: 10 . 1006/meth.2001.1262

McNamara, J. M., Barta, Z., Houston, A. I., and Race, P. (2005). A theoretical investigation of the effect of predators on foraging behaviour and energy reserves. Proc. Biol. Sci. 272, 929-934. doi: 10.1098/rspb.2004.3037

Michel, C., Duclos, M., Cabanac, M., and Richard, D. (2005). Chronic stress reduces body fat content in both obesity-prone and obesity-resistant strains of mice. Horm. Behav. 48, 172-179. doi: 10.1016/j.yhbeh.2005.02.004

Monarca, R. I., da Luz Mathias, M., Wang, D., and Speakman, J. R. (2015a). Predation risk modulates diet-induced obesity in male C57BL/6 mice. Obesity 23, 2059-2065. doi: 10.1002/oby.21193

Monarca, R. I., Mathias, M. D. L., and Speakman, J. R. (2015b). Behavioural and physiological responses of wood mice (Apodemus sylvaticus) to experimental manipulations of predation and starvation risk. Physiol. Behav. 149, 331-339. doi: 10.1016/j.physbeh.2015.06.037 
Morrow, B. A., Redmond, A. J., Roth, R. H., and Elsworth, J. D. (2000). The predator odor, TMT, displays a unique, stress-like pattern of dopaminergic and endocrinological activation in the rat. Brain Res. 864, 146-151. doi: 10. 1016/s0006-8993(00)02174-0

Mueller, B. R., and Bale, T. L. (2008). Sex-specific programming of offspring emotionality after stress early in pregnancy. J. Neurosci. 28, 9055-9065. doi: 10. 1523/JNEUROSCI.1424-08.2008

Nedergaard, J., and Cannon, B. (2013). UCP1 mRNA does not produce heat. Biochim. Biophys. Acta 1831, 943-949. doi: 10.1016/j.bbalip.2013. 01.009

Pagani, J. H., and Rosen, J. B. (2009). The medial hypothalamic defensive circuit and 2,5-dihydro-2,4,5-trimethylthiazoline (TMT) induced fear: comparison of electrolytic and neurotoxic lesions. Brain Res. 1286, 133-146. doi: 10.1016/j. brainres.2009.06.062

Paxinos, G., and Franklin, K. B. J. (2004). The Mouse Brain in Stereotaxic Coordinates. Amsterdam: Gulf Professional Publishing.

Pérez-Gómez, A., Bleymehl, K., Stein, B., Pyrski, M., Birnbaumer, L., Munger, S. D., et al. (2015). Innate predator odor aversion driven by parallel olfactory subsystems that converge in the ventromedial hypothalamus. Curr. Biol. 25, 1340-1346. doi: 10.1016/j.cub.2015.03.026

Rezai-Zadeh, K., Yu, S., Jiang, Y., Laque, A., Schwartzenburg, C., Morrison, C. D., et al. (2014). Leptin receptor neurons in the dorsomedial hypothalamus are key regulators of energy expenditure and body weight, but not food intake. Mol. Metab. 3, 681-693. doi: 10.1016/j.molmet.2014.07.008

Ricquier, D., and Mory, G. (1984). Factors affecting brown adipose tissue activity in animals and man. Clin. Endocrinol. Metab. 13, 501-520. doi: 10.1016/s0300$595 x(84) 80035-3$

Rosen, J. B., Asok, A., and Chakraborty, T. (2015). The smell of fear: innate threat of 2,5-dihydro-2,4,5-trimethylthiazoline, a single molecule component of a predator odor. Front. Neurosci. 9:292. doi: 10.3389/fnins.2015.00292

Sears, R. M., Liu, R.-J., Narayanan, N. S., Sharf, R., Yeckel, M. F., Laubach, M., et al. (2010). Regulation of nucleus accumbens activity by the hypothalamic neuropeptide melanin-concentrating hormone. J. Neurosci. 30, 8263-8273. doi: 10.1523/JNEUROSCI.5858-09.2010

Speakman, J. R. (2007). A nonadaptive scenario explaining the genetic predisposition to obesity: the "predation release" hypothesis. Cell Metab. 6, 5-12. doi: 10.1016/j.cmet.2007.06.004
Staples, L. G., McGregor, I. S., Apfelbach, R., and Hunt, G. E. (2008). Cat odor, but not trimethylthiazoline (fox odor), activates accessory olfactory and defense-related brain regions in rats. Neuroscience 151, 937-947. doi: 10.1016/j. neuroscience.2007.11.039

Staples, L. G., McGregor, I. S., and Hunt, G. E. (2009). Long-lasting FosB/ $\Delta$ FosB immunoreactivity in the rat brain after repeated cat odor exposure. Neurosci. Lett. 462, 157-161. doi: 10.1016/j.neulet.2009.06.069

Sundell, J., Dudek, D., Klemme, I., Koivisto, E., Pusenius, J., and Yl nen, H. (2004). Variation in predation risk and vole feeding behaviour: a field test of the risk allocation hypothesis. Oecologia 139, 157-162. doi: 10.1007/s00442-004-1490-x

Sundell, J., and Norrdahl, K. (2002). Body size-dependent refuges in voles: an alternative explanation of the Chitty effect. Ann. Zool. Fennici. 39, 325-333. http://www.jstor.org/stable/23735831.

Tidhar, W. L., Bonier, F., and Speakman, J. R. (2007). Sex- and concentrationdependent effects of predator feces on seasonal regulation of body mass in the bank vole Clethrionomys glareolus. Horm. Behav. 52, 436-444. doi: 10.1016/j. yhbeh.2007.06.009

Vernet-Maury, E. (1980). "Trimethyl-thiazoline in fox feces: a natural alarming substance for the rat," in Olfaction Taste, Vol. VII (Washington, D.C.: IRL Press).

Vernet-Maury, E., Polak, E. H., and Demael, A. (1984). Structure-activity relationship of stress-inducing odorants in the rat. J. Chem. Ecol. 10, 1007-1018. doi: 10.1007/BF00987509

Wallace, K. J., and Rosen, J. B. (2000). Predator odor as an unconditioned fear stimulus in rats: elicitation of freezing by trimethylthiazoline, a component of fox feces. Behav. Neurosci. 114, 912-922. doi: 10.1037/0735-7044.114.5.912

Conflict of Interest Statement: The authors declare that the research was conducted in the absence of any commercial or financial relationships that could be construed as a potential conflict of interest.

Copyright (C) 2016 Genné-Bacon, Trinko and DiLeone. This is an open-access article distributed under the terms of the Creative Commons Attribution License (CC BY). The use, distribution and reproduction in other forums is permitted, provided the original author(s) or licensor are credited and that the original publication in this journal is cited, in accordance with accepted academic practice. No use, distribution or reproduction is permitted which does not comply with these terms. 